\title{
O IGUALITARISMO LIBERAL DE DWORKIN ${ }^{I}$
}

\author{
Darlei Dall'Agnol*
}

RESUMO $O$ presente artigo apresenta os principais componentes da filosofia política de Dworkin, aqui chamada de "igualitarismo liberal." Para atingir esse objetivo, reconstrói a sua teoria do Direito e sua compreensão do direito fundamental de todos cidadãos ao igual respeito e consideração. Além disso, discute criticamente a sua tentativa de compatibilizar essa igualdade formal, bem como uma concepção mais substancial de igualdade, com a liberdade.

Palavras-chave Liberalismo, Direito, Igualdade, Liberdade, Dworkin

ABSTRACT This paper sorts out the main elements in Dworkin's political philosophy here called "liberal igualitarianism." To reach this aim, it reconstructs his conception of Law and his understanding of the citizens' most fundamental right to equal respect and concern. Moreover, it analyzes his attempt to reconcile this formal equality, as well as a more substantial equality, with freedom.

Keywords Liberalism, Law, Equality, Freedom, Dworkin

* Professor do Centro de Filosofia e Ciências Humanas da Universidade Federal de Santa Catarina. Artigo recebido em maio de 2004 e aprovado em maio de 2005. darlei@cfh.ufsc.br.

1 Texto originalmente apresentado no Seminário sobre Filosofia do Direito na UFSC, em 2003. A sua revisão, em abril de 2004, contou com o apoio do CNPq ao meu projeto atual de pesquisa Seguir uma regra: as implicações das observações de Wittgenstein para o debate metaético entre cognitivistas e não-cognitivistas. Sou grato também ao amigo e colega Delamar Volpato Dutra pelos comentários e sugestões a uma versão preliminar deste artigo.

KRITERION, Belo Horizonte, $n^{\circ}$ 111, Jun/2005, p. 55-69 


\section{Introdução}

Um dos principais problemas da filosofia política e da Teoria do Direito da modernidade tem sido equacionar de forma satisfatória a relação entre liberdade e igualdade. Por um lado, há pensadores, por exemplo Kant, que insistem na primazia da liberdade como fundamento das ações políticas e jurídicas. Por outro, há filósofos, entre eles Aristóteles e Mill, que sustentam que a igualdade é a base da justiça e, consequientemente, deve servir de fio norteador para o estabelecimento de políticas públicas.

As diferenças tornam-se agudas para aqueles que pensam que existe um completo antagonismo entre os ideais da liberdade e da igualdade. Realmente, parece que se uma determinada política pública dá ênfase à liberdade individual, há um crescimento significativo da desigualdade social. Por exemplo, nos períodos de predomínio do neoliberalismo econômico nos anos 1990, houve um crescimento da desigualdade social nos países latino-americanos. No entanto, se a política prioriza a igualdade social, parece que há uma clara necessidade de restringir a liberdade das pessoas. A tentativa de implantação de regimes socialistas, via ditadura do proletariado, é uma clara evidência deste aparente antagonismo entre liberdade e igualdade.

O que torna atrativa a filosofia política de Dworkin, e junto com ela a sua filosofia do Direito, é a tentativa de mostrar que a liberdade e a igualdade não se contradizem, mas se complementam. Mais do que isso, apesar de claramente trabalhar na tradição liberal de autores como Rawls, sua compreensão do liberalismo é sui generis na medida em que acredita que a igualdade é o seu fundamento.

O objetivo deste artigo é discutir a Teoria do Direito de Dworkin à luz de sua filosofia política, que será chamada aqui, por razões que ficarão claras a seguir, de "igualitarismo liberal". A intenção é analisar criticamente a própria noção de igualdade que serve de fundamento para a sua compreensão política do Direito.

\section{Igualitarismo Liberal}

Para compreender em que medida Dworkin reinterpreta os pressupostos fundamentais do liberalismo, é necessário reconstruir algumas críticas que ele fez a autores como Rawls e Nozick. No livro clássico Uma teoria da justiça, publicado originalmente em 1971, Rawls cria um procedimento para estabelecer princípios básicos de justiça que devem reger uma sociedade democrática. Esse procedimento consiste em imaginar uma situação hipotética, chamada de 
"posição original", na qual as pessoas fariam um contrato desses princípios para depois formular uma constituição e fundar as demais instituições necessárias para a co-operação entre os cidadãos. Acontece que essas pessoas estariam numa situação peculiar, a saber, sob o "véu da ignorância“" elas teriam seus próprios interesses, conheceriam parcialmente suas identidades, as leis principais econômicas etc., mas desconheceriam sua efetiva posição na sociedade, por exemplo, se são ricas ou pobres, jovens ou velhas, a raça a que pertencem etc. Se fosse adotado esse procedimento, Rawls argumenta, as pessoas escolheriam os seguintes princípios de justiça: primeiro, todos teriam igual direito às liberdades básicas (liberdade de consciência, liberdade de falar sobre assuntos políticos, liberdade de votar, liberdade para possuir propriedades, liberdade para não ser preso e julgado sem o devido processo etc); segundo, as eventuais diferenças na distribuição de riqueza poderiam ser toleradas se elas fossem vantajosas para todos e atreladas a funções abertas a todos. Finalmente, Rawls sustenta que existe uma regra de prioridade: sempre que esses dois princípios pareçam entrar em conflito, o primeiro deve sobrepor-se ao segundo. Dito de outro modo, as liberdades são mais importantes que as eventuais desigualdades sociais e econômicas.

Ao longo dos 30 anos que se sucederam à publicação de Uma teoria da justiça, Dworkin tem sido um agudo crítico de algumas das idéias de Rawls. Duas objeções possuem importância no presente contexto. Primeira, Dworkin não concorda com a prioridade dada ao primeiro princípio (cf. [1975], p. 17). Considera a tese de Rawls de que qualquer ser racional preferiria, tendo as condições mínimas de vida satisfeitas, incrementar a liberdade e não a riqueza material, uma proposição injustificada. Além disso, Rawls possuiria uma visão conservadora do caráter das pessoas. Isso significa que Dworkin pensa que, mesmo sob o véu da ignorância, as pessoas não necessariamente contratariam os princípios acima mencionados. Elas bem poderiam arriscar e assumir princípios de justiça não igualitários achando que estariam em posições de vantagem sobre os demais. Portanto, segundo Dworkin, a tentativa de Rawls de mostrar que as liberdades básicas são mais importantes do que as diferenças econômicas e sociais simplesmente é falha.

Outra crítica importante, necessária para compreender o igualitarismo liberal, foi feita no artigo "The Original Position". Nele, Dworkin contrapõe o modelo construtivista, procedimental, de Rawls, aos modelos naturalistas de justificação, para mostrar que o que fundamenta o primeiro princípio da justiça é o direito originário que cada pessoa tem de ser respeitada e considerada de modo igualitário (cf. [1975], p. 46-53). Quer dizer, a posição original é caracterizada de tal maneira que fica evidente que a igualdade é o princípio 
fundamental e não as diversas liberdades individuais. Nos termos de Dworkin, "o direito ao igual respeito não é um produto do contrato, mas a condição de admissão na posição original" (Ibidem, p. 51). Por isso, o direito à igualdade de tratamento é devido aos seres humanos enquanto pessoas morais (cf. o próprio Rawls, 1999, p. 511). Conseqüentemente,

a pressuposição mais básica de Rawls não é que as pessoas têm um direito a certas liberdades que Locke e Mill acharam importantes, mas que elas têm um direito ao igual respeito e tratamento no estabelecimento de instituições políticas. (grifos meus). ${ }^{2}$

A conclusão não pode ser outra senão a de que a igualdade é a noção fundamental que dá legitimidade ao primeiro princípio de Rawls. Pode-se ter uma primeira idéia aqui de por que a teoria política de Dworkin mereça ser chamada igualitarismo liberal e não uma forma qualquer de liberalismo.

Com relação à teoria liberal defendida por Nozick em Anarchy, state and utopia, Dworkin concorda que indivíduos possuem direitos e que estes são invioláveis, mas discorda que esses direitos existam independentemente do Estado civil, numa espécie de estado de natureza. Para Nozick, a liberdade é tudo, a igualdade nada, e nisso há uma completa oposição nas visões dos dois filósofos. Dworkin discorda também do papel quase exclusivo dado ao direito à propriedade $\mathrm{e}$, conseqüentemente, da concepção minimalista de Estado e das funções que ele deve cumprir, a saber, de garantir este direito e de zelar pela segurança dos cidadãos. Portanto, Dworkin discorda de Nozick na sua idéia básica, isto é, que se assumirmos seriamente os direitos humanos teremos que condenar as práticas do Estado de Bem-Estar Social. Criar impostos para fins de redistribuição de riqueza não é violar direitos nem uma forma de escravizar indivíduos, argumenta Dworkin. Além disso, apesar do fato de que ele concorda com Nozick que a justiça é na tradição liberal independente de qualquer noção sobre a boa vida, discorda que um liberal deva ser absolutamente cético quanto à melhor forma de viver. Na verdade, ele sustenta que se deve deixar ao indivíduo a decisão sobre como ele(a) quer viver, mas isso não significa que as diferentes formas de viver não devam ser escrutinadas, discutidas e justificadas publicamente. Esse ponto será melhor examinado na última seção deste trabalho.

Como foi dito na Introdução, Dworkin contesta a idéia de que os direitos que asseguram as liberdades básicas estão em conflito real com a igualdade num nível fundamental. Para ele, os direitos individuais só fazem sentido se forem concebidos como necessários para aquilo que a igualdade requer. 
Assim, a questão básica da sua filosofia política não é "quanta igualdade deve-se deixar de lado para respeitar um direito?", mas sim "é este direito necessário para proteger a igualdade?". Dworkin, ao inverter a visão do liberalismo tradicional e da versão rawlsiana deste, pretende defendê-lo da acusação de que ele protege interesses individuais em detrimento do bemestar social. Por isso, Dworkin considera a igualdade o motor do liberalismo. Por subordinar os direitos individuais à idéia de igualdade de respeito e consideração, a teoria política de Dworkin precisa ser denominada de "igualitarismo liberal", e não simplesmente ser conhecida como uma versão, entre outras, de liberalismo. Esta caracterização ficará mais clara a partir da explicitação da noção de direitos humanos — base da filosofia política de Dworkin — que será feita a seguir.

\section{Direitos como Trunfos}

No ensaio "Rights as Trumps", Dworkin defende a idéia de que "direitos são melhor entendidos como trunfos (trumps) sobre alguma justificação de fundo de decisões positivas em vez de estabelecer uma finalidade para a comunidade política como um todo" (1984, p. 152). Ao comparar direitos com um certo tipo de carta para jogar, Dworkin tem como finalidade explicitar a função que esta noção desempenha no discurso político. Assim, se alguém tem um direito (por exemplo, de livre expressão de pensamentos), isso significa que será errado violar esse direito em nome do bem-estar da comunidade defendido pela "justificação de fundo". Por esta expressão, Dworkin dá significação a alguma forma de utilitarismo que, segundo ele, continua a ser a mais influente forma de justificação de políticas públicas nas democracias ocidentais. Deve-se notar, todavia, que, ao falar de direitos como trunfos, Dworkin não está apresentando uma definição exata de "ter um direito", mas, antes, explicitando como eles devem ser entendidos na relação indivíduosociedade.

Dworkin nega, como foi visto, que a noção de direitos individuais esteja em conflito com a igualdade. Nega, também, que defender direitos implique num abandono da noção clássica de bem comum que parece ser realmente o fim último da política. Quer dizer, o bem-estar social não precisa estar em oposição aos direitos individuais. O conflito é, para Dworkin, apenas aparente e de superfície. No fundo, tanto direitos individuais quanto o bem-estar social estão fundados na igualdade.

Para compreender melhor essa tese - extremamente importante sob o ponto de vista filosófico-político e que é a base do igualitarismo liberal -, 
é necessário reconstruir a crítica que Dworkin faz às teorias políticas do bemestar, representadas sobretudo pelo utilitarismo. Tradicionalmente, os utilitaristas opuseram-se à noção de direitos humanos, e Bentham chegou mesmo a considerá-los algo fictício. O princípio fundamental do utilitarismo é que o bem-estar de qualquer indivíduo não pode contar mais do que o bemestar geral, e, portanto, a idéia de que um indivíduo possua direitos que podem se sobrepor ao bem comum é rechaçada por alguns utilitaristas que primam pela maximização da felicidade geral. Esta é geralmente entendida em termos de prazer, no utilitarismo clássico, ou de satisfação de interesses, desejos ou preferências, nas versões contemporâneas do utilitarismo.

Dworkin sustenta que essas teorias possuem uma deficiência no seu modo de justificação. A defesa do bem-estar geral é comumente feita no utilitarismo a partir da noção de que, por exemplo, o prazer é um bem em si. Todavia, ele considera essa idéia absurda para justificar políticas públicas. Assim, se o bemestar é uma noção fundamental da política, então temos que encontrar uma razão melhor para adotá-la. Para ele, esta justificação é dada pela idéia de igualdade. A questão relevante, então, é esta: o que significa igualdade? Num primeiro momento, a igualdade política é definida basicamente como um modo de tratar os cidadãos, isto é, considerá-los como iguais, mostrando a mesma consideração e respeito (equal respect and concern) para com cada um deles (1977, p. 180; 1985, p. 190). Essa é a definição mais explícita de igualdade encontrável na teoria de Dworkin, mas ela é bastante vaga. Uma noção mais substancial de igualdade será discutida mais adiante. Por conseguinte, procurar o bem-estar geral significa considerar cada pessoa uma e não mais do que uma, uma idéia, aliás, presente no utilitarismo clássico (cf. Mill, 1987, p. 81). Esta idéia é também o núcleo central da ética kantiana, segundo Tugendhat (1984, p. 80). Assim, Dworkin mostra que a noção de bem-estar geral, defendida como fim último das ações políticas pelo utilitarismo, está fundada em uma idéia mais fundamental, a saber, na igualdade.

Dworkin pensa, também, que a noção de igualdade é a base da noção de direitos individuais e que estes, em algumas circunstâncias, são trunfos pessoais sobre o bem-estar geral. Nunca é demais lembrar que ele sustenta o fato de o conflito não ser real, de ele não operar num nível fundamental, e que a justificação tanto dos direitos quanto do bem-estar geral é feita a partir da noção de igualdade. Para compreender de forma mais detalhada como isso acontece no caso dos direitos, podem-se examinar os direitos econômicos, por exemplo, o direito a um padrão de vida decente de um indivíduo qualquer que vive em uma sociedade com recursos suficientes para todos. A política econômica dessa sociedade deve procurar incrementar o bem-estar médio, 
e isso significa que, se uma política pública aumentar as condições de vida da comunidade como um todo, ela deve ser escolhida em detrimento de uma política que irá melhorar as condições de um grupo menor. Isso é requerido também pelo igualitarismo liberal, pois, do contrário, os interesses do grupo menor irão se sobrepor aos interesses da comunidade em geral. Todavia, se alguns indivíduos, dadas certas condições especiais de sua vida, como o fato de serem deficientes ou de o mercado não precisar mais de seus talentos etc., acabam tendo um padrão de vida menor que a média geral da comunidade, então tal situação deve ser corrigida, pois o indivíduo tem direito a um padrão mínimo de vida. É dessa maneira que os direitos econômicos são justificados pelo igualitarismo liberal, e aqui começa a se esboçar uma noção mais substancial de igualdade.

É a partir do capítulo 6 de Taking rights seriously que Dworkin apresenta uma defesa mais detalhada dos diferentes direitos. Sustenta que o direito mais fundamental é o direito à igualdade, e essa é, realmente, a premissa básica da sua filosofia política. Se alguém perguntasse "Igualdade de quê?", Dworkin responderia, num primeiro momento, que se trata da igualdade de consideração e respeito requerida mutuamente entre todos os indivíduos. Ela forma também a base das ações políticas e determina projetos governamentais. É exatamente a partir desse direito básico à igualdade que ele justifica os outros direitos legislativos, econômicos, políticos etc. Mas o que é surpreendente para um filósofo que se diz liberal é que, no capítulo 12 do referido livro, Dworkin argumente que não existe o assim chamado direito fundamental à liberdade (1977, p. 266). Obviamente, ele não nega que os indivíduos têm direito a certas liberdades, por exemplo, o direito à tomada de decisões pessoais em questões morais. Todavia, esses direitos são derivados não de um suposto direito geral e abstrato à liberdade como tal, mas do direito à igualdade.

Os direitos políticos também podem ser justificados a partir da igualdade. Uma democracia parlamentar é um modo igualitário de decidir, quais leis devem ser adotadas numa determinada comunidade, entre outras coisas. As leis devem proteger o bem- estar quando, por exemplo, proíbem certos atos criminosos, e é exatamente a igualdade que exige que cada cidadão tenha voz na determinação da forma do bem-estar geral. Portanto, os direitos políticos são justificados a partir da igualdade materializada nas decisões democráticas. Tendo apresentado a noção dworkiniana de direitos e o modo como estes são justificados, pode-se clarificar a sua concepção de direito, pois uma funda-se na outra. 


\section{Uma teoria liberal do Direito?}

Desde a publicação de Taking rights seriously, Dworkin vem sofisticando uma teoria do Direito que eventualmente culmina no livro Law's empire. Dado que ele próprio denomina sua teoria de "liberal", seria necessário caracterizar de forma mais detalhada o que se entende historicamente por liberalismo. Todavia, isso está além dos limites do presente artigo (para uma discussão detalhada do liberalismo, ver Dworkin, 1985, p. 181 et seq.). É preciso, entretanto, manter presentes as principais teses do igualitarismo liberal, que foram brevemente esboçadas anteriormente, para se compreender melhor a sua teoria do Direito. De fato, a filosofia do Direito de Dworkin é elaborada a partir de sua filosofia política.

Inicialmente, Dworkin contrapõe a sua concepção de Direito a duas teorias legalistas: o positivismo jurídico e o utilitarismo (cf. 1977, p. vii). Ambas teriam sido derivadas de Bentham. A primeira sustenta que a verdade de julgamentos legais consiste em fatos sobre as regras que têm sido adotadas pelas instituições sociais, e nada mais. A segunda sustenta que o Direito e suas instituições servem somente ao bem-estar geral. A teoria do Direito de Dworkin contrapõe-se a ambas, mas insere-se no contexto da tradição liberal. Sua base são os direitos humanos que não encontram lugar nem no utilitarismo nem no positivismo jurídico, analisados acima.

Sob o ponto de vista metodológico, Dworkin sustenta que é necessário distinguir, numa teoria do Direito, questões conceituais, metaéticas, de questões normativas. As primeiras dizem respeito ao que se deve entender por expressões como "lei", "propriedade" etc., tantas vezes usadas por advogados, promotores, juízes e poucas vezes definidas claramente. Questões normativas referem-se ao fato de determinadas leis serem justas ou injustas, a quais direitos os indivíduos possuem etc. Disso se segue uma série de lições pedagógicas sobre o ensino do Direito: é importante estabelecer com clareza o significado das expressões que estão sendo usadas; é necessário distinguir questões factuais de valorativas, por exemplo, questões relativas à existência de sistemas legais e questões relativas à sua legitimação etc. Por isso, tão importante quanto ensinar códigos é discutir criticamente as bases filosóficas do Direito.

Quanto à estrutura, a parte normativa do Direito deve, segundo Dworkin, ser formada por três teorias básicas: legislação; adjudicação e concordância (cf. 1977, p. viii). A primeira discute questões de legitimidade, por exemplo, descreve sob que condições um indivíduo ou um grupo está autorizado a emitir leis e quais são essas leis. A segunda estabelece padrões para juízes decidirem casos aplicando a lei e mostra porque eles, e mais ninguém, devem tomar as 
decisões de aplicação das leis. A última discute os limites e a natureza dos deveres que os cidadãos têm de obedecer, as leis, além das punições associadas ao seu não cumprimento. Sem entrar em maiores detalhes sobre cada uma dessas partes, fica clara a estrutura da qual uma teoria completa do Direito deve dar conta.

Por que, alguém poderia perguntar, essa teoria do Direito é liberal? Em primeiro lugar, porque, como já foi salientado, a idéia básica de Dworkin é que direitos são trunfos políticos possuídos por indivíduos. Disso também se segue que esses fins coletivos não podem servir de justificativa para impor algum tipo de dano ou prejuízo aos indivíduos. Essa caracterização dos direitos é formal na medida em que não diz quais são os direitos de que os indivíduos são efetivamente portadores. Todavia, ela representa um claro avanço em relação à teoria dos supostos direitos naturais ou das fundamentações metafísicas dos direitos humanos. Isso quer dizer basicamente que indivíduos têm direitos quando um fim coletivo não é suficiente para negar o que eles querem, têm ou fazem. Aceita essa premissa, institucionalizam-se deveres, pois, se algum indivíduo tem um direito, então outros terão deveres em relação a ele. O Direito poderia ser, então, visto como uma tentativa de sistematização dos direitos e dos deveres e sua efetiva implementação na sociedade.

Para responder, de forma mais precisa, à pergunta feita, é necessário esclarecer, em segundo lugar, que o Direito não é, para Dworkin, uma ciência exata como a matemática, mas está muito mais próximo de uma arte, como a literatura. Por isso, certas questões assumem papel de destaque na sua Teoria do Direito, por exemplo, problemas interpretativos tornam-se proeminentes. Eles não dizem respeito apenas à interpretação da letra da lei, mas à compreensão dos princípios morais que a fundamentam. Num sistema jurídico no qual o Direito consuetudinário é a base das deliberações e das decisões jurídicas, os problemas de interpretação do senso moral comum tornam-se vitais. Por isso, é necessário esclarecer melhor a tese de que o Direito é fundamentalmente uma atividade interpretativa. Como ficará claro, os princípios do igualitarismo liberal são interpretados como sendo operantes no senso moral comum, e é por isso que a Teoria do Direito de Dworkin é liberal.

\section{O Direito como Interpretação}

Tanto em A matter of principle quanto em Law's empire, Dworkin procura defender de forma mais elaborada a idéia de que o Direito é similar a uma forma de arte, mais especificamente, que ele é análogo à literatura. O Direito, portanto, não seria uma ciência exata. A idéia central é a de que o Direito é 
uma questão de interpretação e não de invenção (1985, p. 1). Essa proposição é explicitamente defendida nos três capítulos da segunda parte do livro A matter of principle e no segundo capítulo de Law's empire. Neles, Dworkin analisa a teoria de que não existe uma resposta correta para questões jurídicas, bem como as prováveis implicações desta posição. Contra ela, sustenta que há razões para rejeitar tal ceticismo e afirmar a objetividade das interpretações das leis. A seguir, será examinado como isso é possível.

Para começar, é necessário discutir a questão de saber se há uma resposta correta para os casos controversos e difíceis (hard cases). Um caso controverso é, por definição, um caso no qual não há argumentos absolutos e finais para uma decisão, em que há, por exemplo, mais de um princípio válido que pode ser invocado ou, aparentemente, não há princípio algum claramente explicitado. Para ilustrar quando isso acontece, considere-se o seguinte caso: imagine-se que se viva num país onde a constituição garanta direitos básicos incluindo a proteção às mais diferentes formas de ação autônoma. Suponha-se, agora, que um determinado estado desse país emita uma lei, baseada na idéia da sacralidade da vida, proibindo a prática abortiva, exceto para salvar a vida da mãe. Não seria essa lei inconstitucional, ferindo o direito da mulher de livremente decidir sobre questões que afetam diretamente o seu corpo? Não estaria esta lei ferindo a autonomia garantida pela constituição? O que é um juiz desse estado particular deveria decidir se uma cidadã solicitasse autorização para cometer aborto, baseada em princípios constitucionais e, principalmente, usasse o argumento de que o feto é portador de uma deficiência grave? Deveria garantir a possibilidade de escolha autônoma ou poderia interpretar a constituição como garantidora do direito à vida do feto deficiente? (cf. Dworkin, 1994, p. 7 et seq., para uma análise do famoso caso Roe $v$. Wade, que serviu para formular esse exemplo).

Apesar do fato de que há diferentes versões da teoria que defende que não haveria respostas corretas nos casos controversos, algumas características básicas dessa posição podem ser apontadas: primeiro, sendo as leis vagas, sempre haverá um espaço para uma livre interpretação na sua aplicação (Dworkin, 1985, p. 128); segundo, dados os permanentes desacordos sobre princípios fundamentais, estes não poderiam ser definitivamente demonstrados (Ibidem, p. 137). Nesses casos, haveria um espaço para a discrição (discretion) e, por exemplo, um juiz poderia aplicar um princípio ou outro. Dworkin, todavia, procura mostrar que, apesar de esse aparente dilema moral parecer insolúvel, é possível chegar a uma resposta correta nos casos controversos. O modo como ele procura resolver o caso apresentado acima será discutido a seguir.

É importante salientar, agora, que Dworkin defende a idéia de que a prática jurídica nãoé apenas um exercício eventual de interpretação, mas que a essência 
do Direito depende de uma prática hermenêutica. O Direito assim concebido é fundamentalmente um fenômeno político. Foi por este motivo que a filosofia política de Dworkin, o seu igualitarismo liberal, foi apresentada antes de uma explicitação da sua concepção de Direito. Disso se segue que advogados, juízes, promotores, jurisconsultos, jusfilósofos etc. devem pensar suas práticas e teorias dentro de um determinado contexto sociopolítico. Todavia, isso não significa que o Direito seja uma questão de interpretação subjetiva ou partidarista. Para evitar essa visão parcial, é necessário aprofundar a tese de que o Direito é, fundamentalmente, uma atividade hermenêutica.

Como foi salientado, a comparação favorita de Dworkin do Direito é com a literatura e não com as ciências exatas. No capitulo "How law is like literature," ele explicitamente sugere que os estudantes e profissionais do Direito devam dedicar-se à literatura e a outras formas de expressão artística. Tem-se aqui outra boa pista de como Dworkin pensaria o ensino do Direito: além do contato com as normas expressas nos diferentes códigos, ele deve fornecer técnicas hermenêuticas sofisticadas de compreensão e interpretação da lei. Alguns problemas tradicionais da hermenêutica jurídica devem ser aqui mencionados: a necessidade de aplicação contextualizada dos princípios gerais; a idéia da historicidade das produções e da racionalidade humanas; a estrutura de horizonte das interpretações, isto é, a importância do contexto etc. Além disso, é importante destacar que há várias questões hermenêuticas que precisam de aprofundamento: se se deve compreender a lei segundo a letra gramatical ou segundo o espírito; a necessidade de uma técnica sistemática, a saber, de ver a constituição, os diferentes códigos e os decretos como um todo; a importância da consideração da intenção ou da vontade do legislador etc. Essas questões devem ser debatidas, porque o Direito está mais próximo da arte interpretativa do que da ciência explicativa. Isso não significa, como foi apontado, entregarse a alguma forma de ceticismo ou relativismo.

As perguntas relevantes, agora, são as seguintes: como Dworkin defende a objetividade da interpretação jurídica? Como ele resolve os casos controversos? A resposta a estas questões não é muito fácil, pois a interpretação e a aplicação da lei tornam-se uma tarefa verdadeiramente hercúlea. Ciente disso, Dworkin imagina um juiz com habilidades super-humanas, chamado Hércules (1977, p. 105 et seq.), que poderia resolver casos controversos de forma objetiva e correta. Deve-se salientar inicialmente que Hércules aceita as leis vigentes, reconhece o dever de seguir as decisões anteriores, sabe que são as leis que criam e extinguem direitos etc., mas que ele deve interpretar uma série de princípios básicos do Direito e, mais amplamente, da justiça, para apoiar suas decisões sobre os eventuais casos controversos. Para ilustrar como 
isso seria feito, pode-se retomar o exemplo bioético apresentado anteriormente. Para decidir esse caso, Hércules precisa construir uma teoria política completa que justifique a constituição como um todo, isto é, ele deve ter uma filosofia política capaz de explicitar o lugar da justiça (fairness) na sociedade. Deve, também, fazer uma teoria constitucional, ou seja, estabelecer quais são os princípios e políticas que devem ser seguidos. No caso do sistema angloamericano, isso pode incluir a interpretação da common law, visto que o Direito é fundamentalmente consuetudinário. Eventualmente, a decisão de Hércules deve ser a de que o princípio da sacralidade da vida deva realmente ser respeitado, mas este não seria ferido se fosse concedido o direito de aborto em casos nos quais há uma deficiência severa na formação do feto. Essa decisão poderia ser fundamentada na interpretação de um princípio constitucional, a saber, aquele que garante a autonomia que, nesse caso, se sobreporia ao valor intrínseco da vida (cf. Dworkin, 1994, p. 7 et seq., para uma análise da decisão da Suprema Corte americana, tomada em 1973, sobre o caso Roe v. Wade). Percebe-se, desse modo, como o Direito é uma arte interpretativa, inclusive dos princípios fundamentais do senso moral.

\section{5. Ética e Justiça}

Nesta seção, pretende-se retomar brevemente a relação entre o Direito e a filosofia política de Dworkin. Já deve estar bastante claro o lugar central reservado à igualdade no seu sistema filosófico. Suas posições têm sido chamadas, neste trabalho, de "igualitarismo liberal" e, até o presente momento, somente uma concepção mais formal de igualdade foi abordada, a saber, a de igual consideração e respeito. Todavia, também já foi salientado que a defesa que Dworkin faz dos direitos econômicos introduz uma concepção mais substancial de igualdade. Entretanto, há alguns pontos da sua filosofia política que precisam ser melhor esclarecidos para que isso possa ser melhor compreendido. Desde o final da década de 1980, Dworkin estabelece uma base mais sólida de seu igualitarismo liberal, pois defende de forma enfática uma concepção substantiva de igualdade baseada, por exemplo, na igual distribuição de recursos.

Antes de aprofundar esse ponto, é necessário ressaltar, novamente, que Dworkin se afasta das teorias liberais à la Rawls que pretendem dar conta da justiça em termos puramente políticos. Tal separação entre ética e política é, segundo Dworkin, esquizofrênica, pois nela não podemos reconhecer as convicções mais elementares da vida moral quotidiana. Ele sustenta que um Estado liberal deve, realmente, ser neutro quanto às diferentes formas de vida, 
isto é, ele não deve impor uma concepção particular de vida feliz. Todavia, deve também garantir as condições mínimas para que todas as formas de vida possam realizar seus projetos de vida boa. Portanto, há uma continuidade entre ética e política: uma forma de vida só pode realizar-se num contexto social (cf. Mulhall e Swift, 1996, p. 276-308, para uma análise mais detalhada desse ponto).

A igualdade formal, isto é, a idéia de que todos devem ser respeitados e tratados igualmente, já foi suficientemente analisada. Resta, agora, clarificar melhor um tipo de igualdade mais substantivo, a saber, a igualdade de recursos, de oportunidades etc. Como fica claro, por exemplo, em A matter of principle, Dworkin sustenta que no liberalismo a idéia de igualdade como ideal político não é completamente esgotada pelo respeito e consideração mútuos (1985, p. 190). Um outro princípio básico do igualitarismo liberal requer que "o governo trate todos aqueles que estão sob sua responsabilidade igualmente na distribuição de algum recurso de oportunidade" (Ibidem, p. 190, grifo no original). Como pode ser visto, Dworkin sustenta que certas condições mínimas devem ser garantidas pelo Estado para que os cidadãos realizem seus projetos existenciais. $\mathrm{O}$ acesso à educação básica, por exemplo, é uma condição necessária para que haja sucesso no estabelecimento de metas dos diversos planos de vida e a sua efetiva realização.

Quanto à igual distribuição de recursos, Dworkin sustenta que eles

devem de algum modo figurar como parâmetros porque não podemos descrever o desafio de viver bem sem fazer algumas pressuposições sobre os recursos que devem estar disponíveis para uma boa vida. Os recursos não podem contar apenas como limitações porque não podemos fazer sentido da melhor vida possível abstraindo completamente de suas circunstâncias econômicas (...) (grifos meus). ${ }^{3}$

Assim, aquilo que Dworkin chama de "igualdade liberal" consiste numa visão que considera que uma distribuição justa de recursos é atingida quando todos podem usufruir igualmente daquelas condições que são necessárias para a sua forma de vida. Conseqüentemente, as desigualdades de recursos (terras, casas etc.) devem ser retificadas pela simples transferência e as desigualdades pessoais (diferenças de talentos e saúde) devem ser compensadas por um sistema de impostos redistributivos. Como pode ser visto, o igualitarismo liberal de Dworkin não está fundado apenas numa noção formal de igualdade. Lectures on Human Values. Ann Arbor: University of Michigan Press, 1995. p. 259. 


\section{Observação Final}

Não é possível fazer uma avaliação crítica completa da filosofia política de Dworkin aqui nem de sua teoria do Direito. Entretanto, uma última observação precisa ser feita. A filosofia política de Dworkin parece ser algum tipo de liberalismo idealizado. Isso quer dizer o seguinte: teoricamente, parece não haver realmente conflito entre liberdade e igualdade, mas nas práticas das economias capitalistas, nas quais o seu igualitarismo liberal encontra seu lugar natural, há certamente um antagonismo entre esses ideais políticos. Por isso, autores como Rawls, ao darem prioridade para as liberdades e imediatamente reconhecerem que elas produzem desigualdades sociais, parecem ser mais realistas. Portanto, ao colocar a igualdade como fundamento do liberalismo, Dworkin é levado a aceitar, em primeiro lugar, um conceito meramente formal de igualdade (igual respeito e consideração) e, em segundo, tipos de igualdade mais substantivos (de recursos, de oportunidades etc.), mas que ainda estão longe de satisfazerem uma versão mais radical de igualitarismo. A pergunta que permanece para reflexão é esta: seria o igualitarismo liberal meramente uma nova utopia ou, de fato, a forma que as sociedades ocidentais atuais devem assumir como princípio ético?

\section{Referências}

ARISTOTLE. Ethica Nicomachea. Oxford: Oxonni e Typographeo Clarendoniano, 1954.

DARWALL, S. (ed.) Equal Freedom. Selected Tanner Lectures on Human Values. Ann Arbor: University of Michigan Press, 1995.

DWORKIN, R. The Original Position. [1975]. In: DANIELS, N. Reading Rawls. Critical studies in Rawls' A theory of justice. Stanford: University Press, 1989. p.16-53.

Taking rights seriously. London: Duckworth, 1977.

Rights as Trumps. In: WALDRON, J. Theories of rights. Oxford: University

Press, 1984. p.153-167.

. A matter of principle. Cambridge/London: Harvard University Press, 1985. . Law's empire. Cambridge/London: Harvard University Press, 1986.

Life's dominion. An argument about abortion, euthanasia, and individual freedom. New York: Vintage Books, 1994.

"Foundations of Liberal Equality" In: DARWALL, S. (Ed.). Equal Freedom.

Selected Tanner Lectures on Human Values. Ann Arbor: University of Michigan Press, 1995.

KANT, I. Grundlegung zur Metaphysik der Sitten. Frankfurt am Main: Suhrkamp, 1968. 
MILL, J. S. Utilitariansim. New York: Prometheus Books, 1987.

MULHALL, S.; SWIFT, A. Liberals \& communitarians. Oxford: Blackwell, 1996.

NOZICK, R. Anarchy, state, and utopia. Oxford: Blackwell, 1995.

RAWLS, J. A theory of justice. A revised edition. Oxford: University Press, 1999. TUGENDHAT, E. Vorlesungen ueber ethik. Frankfurt am Main: Suhrkamp, 1984. 